\title{
EVOLUCIÓN DE LA IGUALDAD DESDE LA CONSTITUCIÓN DE 1978: DEL PATRIARCADO FUERTE HACIA LA IGUALDAD DE GÉNERO
}

\section{EVOLUTION OF EQUALITY SINCE THE 1978 CONSTITUTION: FROM STRONG PATRIARCHY TO GENDER EQUALITY}

\author{
José Fernando Lousada Arochena \\ Tribunal Superior de Justicia de Galicia y Universidad de A Coruña - España \\ josefernandolousada@gmail.com
}

Resumen: El estudio analiza la evolución del ordenamiento jurídico español en materia de igualdad de mujeres y hombres desde la Constitución de 1978. A estos efectos, se explicitan, con carácter previo, los distintos modelos teóricos de ordenamientos jurídicos en orden al tratamiento dado a la igualdad de mujeres y hombres: patriarcado fuerte, que se corresponde con un derecho machista; patriarcado moderado, que se corresponde con un derecho masculino construido sobre leyes de igualdad basadas en la comparativa (leyes de igualdad clásicas); e igualdad de género, construida sobre leyes de igualdad basadas en la superación de los prejuicios asociados al sexo (leyes de igualdad modernas). Sobre esta taxonomía conceptual, en España se comprueba que la Constitución de 1978 permitió la superación del patriarcado fuerte, evolucionando progresivamente hacia la igualdad de género, todavía no conseguida, pero tendencialmente buscada gracias a las leyes de igualdad transversales dictadas en este Siglo XXI.

Palabras Claves: igualdad de género, modelos teóricos legales, derecho español.

\begin{abstract}
The study analyzes the evolution of the Spanish legal system in matters of equality between women and men since the 1978 Constitution. For this purpose, the different theoretical models of legal systems are made explicit in order to treat equality of women and men: strong patriarchy, which corresponds to a sexist right; moderate patriarchy, which corresponds to a male right built on comparative-based equality laws (classical equality laws); and gender equality, built on equality laws based on overcoming prejudices associated with sex (modern equality laws). On this conceptual taxonomy, in Spain it is verified that the Constitution of 1978 allowed the overcoming of the strong patriarchy, progressively evolving towards gender equality, not yet achieved, but tended to be sought thanks to the transversal equality laws issued in this 21st century.
\end{abstract}

Keywords: gender equality, theoretical legal models, Spanish law. 
Siendo el objeto de nuestro estudio el análisis de la evolución de la igualdad desde la Constitución Española de 1978, es necesario explicitar, con carácter previo, los distintos modelos teóricos de ordenamientos jurídicos en relación con el tratamiento dado a la igualdad de mujeres y hombres ${ }^{1}$. Hecho esto, se puede comprobar cuál fue el punto de partida existente en el momento de aprobación de la Constitución Española de 1978 y cómo desde ese punto de partida se ha evolucionado hasta la situación actual.

\section{Modelos teóricos de tratamiento jurídico de la igualdad de mujeres y hombres}

\subsection{Ordenamientos jurídicos patriarcales fuertes y moderados}

Podemos calificar a un ordenamiento jurídico como patriarcal cuando, por la letra de sus normas o debido a su aplicación, se legitima total o parcialmente la subordinación de la mujer y la violencia de género. Un ordenamiento jurídico patriarcal solo se concibe en el contexto de una sociedad donde no existe una igualdad de los sexos, lo que opera como una fuente de legitimación de las situaciones de desigualdad o violencia de género en él existentes o por él toleradas (desigualdad / violencia estructural). El mismo ordenamiento jurídico patriarcal constituye, dentro de una sociedad no igualitaria, una manifestación más de desigualdad y/o violencia de género bien por la letra de sus normas (desigualdad / violencia normativa), bien por el sesgo de quienes las aplican (desigualdad / violencia institucional), bien (lo más usual en la Historia) por ambas circunstancias (desigualdad / violencia normativa + institucional).

Bajo esta calificación se podrían incluir la práctica totalidad de los ordenamientos jurídicos conocidos desde los Orígenes de la Civilización. Y es que la discriminación por razón de sexo (o, más técnicamente, por razón de género: el género abarca las diferencias socioculturales asociadas al sexo como mera diferencia física) es la discriminación con una mayor extensión espacial (en todos los lugares), temporal (en todas las épocas) y modal (desde la violencia de género hasta el paternalismo protector), a lo que coadyuva su acumulabilidad a otras discriminaciones (discriminación múltiple).

Ahora bien, existen al menos dos grandes grupos de ordenamientos jurídicos patriarcales: los fuertes (derecho machista) y los moderados (derecho masculino).

\footnotetext{
${ }^{1}$ Para la explicación del contenido de los distintos modelos teóricos, se han seguido en particular las siguientes aportaciones doctrinales: María Ángeles BARRĖRE UNZUETA, Feminismo y Derecho (Fragmentos para un derecho antisubordiscriminatorio), Editorial Olejnik (Santiago de Chile, 2019); Juana María GIL RUíz (coord.) El Convenio de Estambul como marco de derecho antisubordiscriminatorio, Editorial Dykinson (Madrid, 2018); José Fernando LOUSADA AROCHENA, El derecho fundamental a la igualdad efectiva de mujeres y hombres, Tirant lo Blanch (Valencia, 2014), y El enjuiciamiento de género, Editorial Dykinson (Madrid, 2020); Asunción VENTURA FRANCH / Santiago GARCÍA CAMPÁ (coords.), El derecho a la igualdad efectiva de mujeres y hombres. Una evaluación del primer decenio de la Ley Orgánica 3/2007, Editorial Aranzadi (Madrid, 2018).

IQUAL. REVISTA DE GÉNERO E IGUALDAD, 2022, 5, 1-27 
Un ordenamiento jurídico patriarcal es fuerte cuando se considera explícitamente en la letra de la ley que el hombre es el único posible sujeto de derecho con capacidad plena, mientras que la mujer no la tiene o la tiene restringida debiendo ser suplida por un hombre. Tal estatus jurídico ampara la desigualdad y la violencia de género, bien porque la mujer se considera propiedad del padre o del marido, bien porque debe ser corregida ante comportamientos desviados, bien porque la supuesta fragilidad de su sexo justifica imponerle decisiones sobre su vida, bien porque supuestamente le gusta ser sometida en particular en las relaciones de pareja, bien porque la mujer es fisiológicamente inferior al hombre o está destinada por designio de la naturaleza a determinadas labores, como las de crianza y cuidado, bien por tantas otras razones irrazonables que pretende justificar la supuesta sumisión natural de la mujer al hombre.

Un ordenamiento jurídico patriarcal es moderado cuando se reconoce el principio de igualdad de mujeres y hombres, incluso en los textos constitucionales, pero no se pretende acabar con los estereotipos de género con los cuales, en los previos ordenamientos patriarcales fuertes, se han construido unas normas que perviven tras la transición al ordenamiento patriarcal moderado, y en los cuales se sustentan las estructuras sociales en que las normas jurídicas se aplican. De ahí que en los ordenamientos patriarcales moderados se mantiene la masculinidad de las normas y se toleran las estructuras sociales patriarcales; o sea, estamos ante un derecho masculino.

En la Civilización Occidental, la primera etapa (ordenamiento patriarcal fuerte que se corresponde con un derecho machista) se remonta a sus albores en Grecia y Roma, sin que las revoluciones liberales (a pesar de proclamar la igualdad, que resultó ser solo igualdad de los hombres) cambiasen dicho panorama (en el Siglo XIX, las mujeres estaban privadas del voto y la educación, su acceso al trabajo estaba limitado, y las esposas debían sumisión a la potestad de sus padres y sus esposos). La transición a la segunda etapa (ordenamiento patriarcal débil que se corresponde con un derecho masculino) se produce bien entrado el Siglo XX (y en España, con cierto retraso, esa transición no comienza a acaecer hasta el segundo lustro de la década de los setenta).

\subsection{Las leyes de igualdad clásicas}

Si bien la transición del derecho machista al derecho masculino no ha permitido erradicar la desigualdad o la violencia de género, ello no supone desconocer que se trata de un gran avance histórico. Gracias a la primera ola del Feminismo, en los países más avanzados se implanta el principio de igualdad de mujeres y hombres, incluso en los textos constitucionales, y se reconocen, desde finales del Siglo XIX y en la primera mitad del XX, el voto femenino, el acceso a la educación, o la patria potestad conjunta, y se eliminan prohibiciones o restricciones para trabajar con algunos derechos sociales como la cobertura de la maternidad. A estos importantes avances normativos los denominaremos leyes de igualdad clásicas, caracterizadas por las tres notas siguientes: 
(1) por ser leyes sectoriales en cuanto solo se aplican a sectores de la realidad donde, a través de un juicio de comparación, se aprecia la existencia de una desigualdad irrazonable entre mujeres y hombres (lo que convierte la lucha por la igualdad en una inacabable tarea de comparación de situaciones y constante argumentación de la concreta irrazonabilidad) que se resuelve a través de la asimilación de los derechos de aquellas a los derechos de estos (asumiendo así la situación del hombre como modelo);

(2) por estar basadas en la igualdad formal, buscando la igualdad en la letra de la ley pero sin preocuparse de la igualdad efectiva, de ahí que el reconocimiento formal del derecho puede quedarse en todo o en parte en la letra de la ley sin que tenga repercusión práctica o sin que tenga toda la repercusión práctica que debería tener; $y$

(3) por construirse sobre el concepto de sexo como si los estereotipos de género no existieran (se trata de leyes sex blind, literalmente traducido sexo ciego), con lo cual el perjuicio de género en el cual se justificaba la diferencia de la mujer respecto al hombre permanece incólume o cuasi incólume (un efecto colateral de las leyes sex blind es que, en vez de eliminar o reformar los derechos protectores de las mujeres, posibilitan su extensión a ambos sexos, generando el espejismo del varón discriminado).

Un ejemplo muy claro de leyes de igualdad clásicas son las leyes de reconocimiento del derecho al sufragio femenino: son leyes sectoriales porque la igualdad la aplican solo al derecho al sufragio, de manera que con sus argumentos no se justificarían otras extensiones de derechos, sino que cada caso debería ser analizado conforme al juicio de comparación; son leyes basadas en la igualdad formal porque se ciñen a igualar legalmente pero no se preocupan de si las mujeres efectivamente votan de manera libre o si efectivamente son candidatas; y son leyes que pivotan sobre el sexo sin considerar los roles de género subyacentes que justificaban la negación del derecho al voto en la supuesta incompetencia de las mujeres en las cosas de la política, con lo cual el prejuicio permanecerá cuasi intacto y acabará manifestándose de otras maneras diferentes, como son el déficit de mujeres en cargos electos, la escasa implicación de los partidos políticos y de sus programas en las cuestiones de igualdad, o los ataques a las mujeres dedicadas a política por su supuesta incompetencia en las cosas de la política.

\subsection{Carencias de las leyes de igualdad clásicas}

Las leyes de igualdad clásicas, siendo una condición necesaria para avanzar en igualdad, no son una condición suficiente porque no pretenden acabar con los estereotipos de género, lo que explica las limitaciones de esas leyes: las mujeres se educan e incluso obtienen títulos universitarios, pero son los hombres quienes acceden más fácilmente al trabajo (las mujeres acababan enfrentadas al llamado dilema de Wollstonecraft: o trabajan renunciando a la maternidad, o son madres renunciando al trabajo, y en ambos casos se consolida el statu quo; buscando evitar el dilema en sus términos más extremos, se opta por la salida temporal del mercado de trabajo para la 
maternidad, pero ello desprofesionaliza a la trabajadora: es el efecto grifo que gotea); también los hombres son quienes más fácilmente progresan en el trabajo (las mujeres sufren el ceiling glass / techo de cristal, el sticky floor / suelo pegajoso, o las paredes de hormigón o segregación vertical); se enquistan las brechas de género (económica, salarial o pensional; también la digital); las mujeres pueden votar, pero los elegidos son hombres mientras que las mujeres, como mucho, consiguen puestos sin poder real (son las usualmente llamadas mujeres florero: se trata del fenómeno denominado tokenismo).

Incluso cuando las mujeres acceden a trabajos o a ámbitos de poder masculinizados y esos trabajos o ámbitos de poder se transmutan en feminizados, las condiciones de empleo o su valoración empeora. Se ha dicho muy gráficamente que las mujeres suben (o las dejan subir) a barcos que se hunden, sin que sea relevante discernir aquí si las dejan subir porque se hunden o se hunden porque han subido. Mientras que cuando en un empleo feminizado entran hombres los salarios mejoran, e incluso cuando el número de hombres no es significativo como para propiciar esa mejora, la minoría de hombres progresa más fácilmente (es lo que se conoce como la escalera de cristal).

A veces se ha utilizado para explicar todas estas situaciones la metáfora de las casas (siendo la casa el entramado jurídico y social): cuando la mujer, tradicionalmente destinada a la casa de lo privado (la familia), ha pretendido acceder a la casa de lo público (la política y el trabajo), ocupada por los hombres, las leyes de igualdad clásicas le han permitido entrar, pero se encuentra con que la casa de lo público está construida para los hombres (lo que la conduce a un asimilacionismo al modelo masculino).

En los ordenamientos patriarcales moderados, aunque se achican los espacios de legitimación de las violencias de género, muchos se mantienen: las violencias en el matrimonio, en la relación de pareja o en la familia se invisibilizan como cuestiones privadas; el asesinato / homicidio cometido por la pareja o la ex pareja se consideran crimen pasional, sin apreciar la existencia de un componente de género; si existe provocación, si la víctima lleva una vida disoluta, o si no se resiste de una manera suficiente, se presume el consentimiento de la mujer a una agresión sexual; el acoso sexual se considera como una forma más de acercamiento sexual, luego no es un ilícito.

\subsection{La segunda ola del Feminismo}

La identificación del género como causa de la subordinación femenina obedece a las aportaciones del movimiento de liberación de la mujer (o woman's lib), también llamado la segunda ola del Feminismo. Su punto de arranque lo encontramos en la obra de Simone de Beauvoir El segundo sexo (1949), en la cual se sostiene que lo que se entiende por mujer no es un producto natural ("no se nace mujer, se llega a serlo" es la tan conocida afirmación con la que comienza la segunda parte de su obra) porque, aunque existan diferencias fisiológicas entre los sexos (la maternidad y una cierta 
inferioridad física), de ello no se deduce la jerarquía entre lo masculino y lo femenino, que es una construcción social y cultural que expulsa a la mujer del mundo del conocimiento, de la cultura o de la política (lo que se identifica a lo largo de la obra con la trascendencia), y que la recluye en las labores reproductivas, domésticas y de cuidado (lo que se identifica con la inmanencia). De ahí que las mujeres no puedan oponer un contrauniverso femenino a todo el universo masculino. Las mujeres simplemente son una alteralidad de los hombres como auténticos sujetos definidores de todo el universo.

Motivó la difusión de esta obra una nueva ola de estudios feministas entre los que destacan La mística de la feminidad (1963), de Betty Friedan, que es una crítica a la política de exaltación del ama de casa que lleva a las mujeres, abandonando formación y expectativas laborales, a tareas domésticas y depender de sus maridos, sin aspiraciones vitales, generando "el malestar que no tiene nombre". O Política sexual (1970), de Kate Millet, para quien la sexualidad ostenta un cariz político: "lo sexual es político".

Nace así el movimiento de liberación de la mujer, que encuentra la causa de la discriminación no en el sexo (esto es, en las diferencias físicas entre mujeres y hombres) sino en el género (esto es, el añadido sociocultural). Tradicionalmente, el sexo ha invisibilizado el género a través de un proceso de naturalización del añadido sociocultural (por ejemplo, considerando la sumisión de las mujeres, o que estas se encarguen de los cuidados, como unas características naturales del sexo femenino). Con el análisis de género se amplía considerablemente el horizonte de las reivindicaciones feministas porque no basta ya con tener derechos si esos derechos no remueven los estereotipos de género, surgiendo nuevas ideas fuerza del derecho antidiscriminatorio como la antisubordinación, el empoderamiento o (recientemente) el liderazgo femenino.

\subsection{La Teoría Feminista del Derecho}

Gracias a la aplicación del análisis de género al Derecho, se ha profundizado en las críticas al Derecho que desde siempre han acompañado al movimiento feminista desde sus mismísimos orígenes. Pero ahora las críticas no se concretan en una vindicación de derechos particulares, sino en una crítica general del Derecho a través de diversas elaboraciones encuadradas bajo el nombre de Feminist Jurisprudence o Teoría Feminista del Derecho. Su tesis central emparenta con los Critical Legal Studies, o Teoría Crítica del Derecho, que, en términos muy básicos, sostiene que el Derecho no es Razón, sino que es Poder. Tal tesis central es la crítica de la objetividad del ordenamiento jurídico: el Derecho no representa la Razón Universal, sino la de los hombres en cuanto detentadores del Poder. De este modo, y en la medida en que los varones ejercen el poder social y estatal y su voluntad es la voluntad general que se expresa a través de la ley es cómo la voluntad de una parte de la sociedad se eleva a moralidad y se identifica con la racionalidad jurídica: la ley neutra, general y abstracta crea el mito de una 
voluntad elevada y omnipresente que acaba institucionalizando el poder de una parte de la sociedad sobre todos los seres humanos que la integran.

Ha permitido la Teoría Feminista del Derecho verificar la existencia de una discriminación sistémica, institucional o difusa en las relaciones jurídicas: los prejuicios sociales y culturales asociados al sexo sobre los cuales se sustenta el patriarcado (es decir, el género) han servido para construir la totalidad de un ordenamiento jurídico que se dice neutro, de ahí que (dada la omnipresencia y la invisibilidad de los prejuicios de género) la discriminación no sea detectable y/o corregible según unas leyes de igualdad basadas en la comparación con un modelo masculino y en la igualación de la mujer a ese modelo (comparación + asimilacionismo), entre otras razones, por las siguientes:

(1) porque la extensión formal a las mujeres de derechos pensados para los hombres conduce a nuevas desigualdades reales (por ejemplo, se les permite trabajar, pero el derecho del trabajo, construido sobre un modelo masculino en el cual obviamente no se contempla la maternidad, las sitúa en desventaja frente a los hombres, obligándolas a decidir entre un trabajo sin maternidad o una maternidad sin trabajo);

(2) porque cuanto más lejos esté una mujer individualmente considerada del modelo masculino tomado como referencia más difícil resultará encontrar un módulo de comparación que permita la aplicación de unas leyes de igualdad basadas en la comparación (a pesar de que en esas circunstancias sería cuando más necesario resultaría aplicar la igualdad a la mujer en cuestión debido a su marginalidad); y

(3) porque no es posible conceder a las mujeres (si no es aparentando conceder privilegios injustificados frente a la situación de los hombres) derechos inexistentes en un modelo masculino (así, la protección solo de mujeres frente a la violencia de género aún hoy día se sigue valorando por amplios sectores de la opinión pública como un privilegio injustificado; las acciones positivas se ven como situaciones excepcionales).

\subsection{Las leyes de igualdad modernas}

Verificada la existencia de una discriminación sistémica, institucional o difusa basada en el género (no en el sexo), ello trae de suyo la insuficiencia de una conceptualización de la igualdad exclusivamente basada en la comparativa para acabar con la discriminación. Se necesita, además, integrar la dimensión de género en el Derecho, incorporando elementos tendentes a la equiparación de ambos sexos a través del empoderamiento de las mujeres y evitando elementos donde se perpetúe su subordinación a los hombres a través de estereotipos de dominación. $Y$ es que una adecuada respuesta jurídica a una discriminación sistémica, institucional o difusa obliga a cuestionar el modelo de referencia para remover la situación de subordinación de las mujeres $y$, en su consecuencia, para empoderarla de modo efectivo frente a los hombres.

IQUAL. REVISTA DE GÉNERO E IGUALDAD, 2022, 5, 1-27 
No se trata (si lo queremos decir de modo metafórico) de repartir la tarta de los hombres con las mujeres, sino de cambiar la receta de la tarta; ni de permitir a las mujeres vestir con el traje chaqueta masculino, sino de hacer un traje que les quede a las mujeres igual de bien que a los hombres a los efectos de satisfacer sus aspiraciones, necesidades y preocupaciones en una igual medida que satisface las de los hombres.

A través del cuestionamiento del modelo de referencia para remover la situación de subordinación de las mujeres $y$, en su consecuencia, para empoderarla frente a los hombres, el análisis de género en el Derecho ha determinado la revisión de múltiples planteamientos antes totalmente arraigados: los delitos sexuales se construyen sobre la existencia de violencia, no sobre la negativa de la víctima (no es necesario el no para que haya delito); el matrimonio no priva de su capacidad a la mujer, ni justifica su violación en base a un supuesto débito conyugal; la violencia doméstica deja de ser una cuestión amparada por la intimidad familiar; la regulación del aborto se debe edificar sobre la perspectiva de la salud de las mujeres y de su autodeterminación; los deberes de cuidado de hijos/as y familiares dependientes deben asumirse en corresponsabilidad, etc.

Como fruto de esa revisión, aparecen o se recrean derechos (como los derechos de protección frente a la violencia de género conformando un derecho fundamental a vivir sin violencia de género, los derechos reproductivos, los derechos de maternidad, la conciliación dirigida hacia la corresponsabilidad o la democracia paritaria) difícil (rectius imposible) de justificar aplicando conceptos basados en la comparación / asimilación. El análisis de género en el Derecho obliga a superar la idea de que la igualdad de los sexos es solo un principio (de igualdad de trato) o una prohibición (de discriminación) para (sin dejar de operar como principio y como prohibición) ser sobre todo un derecho fundamental que, tras la aplicación del análisis de género en cada sector de la realidad se concreta en derechos a la igualdad en cada uno de esos sectores.

El cuestionamiento del modelo de referencia y la integración de la dimensión de género (que son las dos operaciones básicas de la Teoría Feminista del Derecho), se han condensado conceptualmente en el denominado principio de transversalidad de la dimensión de género, o principio de transversalidad de la dimensión de la igualdad de trato y oportunidades de mujeres y hombres, o más sencillamente denominado perspectiva de género. Así las cosas, la integración de una manera activa de la perspectiva de género en la elaboración y en la aplicación de la totalidad de las normas jurídicas (incluyendo la aplicación judicial: enjuiciamiento de género) y, en general, de la totalidad de las políticas públicas, es la única manera de responder con igual generalidad al problema general de la discriminación sistémica, institucional o difusa. Podríamos hablar de una universalidad objetiva de la igualdad: la igualdad se aplica a todo el ordenamiento jurídico: y si se hace bien todas las leyes se convertirían en leyes de garantía / promoción de la igualdad. También podríamos hablar de una universalidad 
subjetiva de la igualdad: la igualdad obliga a todos los operadores/as jurídicos: y si se hace bien todos los operadores/as jurídicos nos convertiríamos en agentes de igualdad.

Pero la aprobación de estas leyes de igualdad modernas no garantiza ni que todas las normas jurídicas se comprometan con la igualdad efectiva de mujeres y hombres, ni que estas se apliquen adecuadamente por quienes aplican el ordenamiento jurídico, ni que toda la sociedad asuma el valor de la igualdad erradicando los estereotipos de género. De ahí que el patriarcado siga vigente, aunque se encuentre en retroceso a lo menos en los países más avanzados en materia de igualdad de género, y ello sin perjuicio de los vaivenes para atrás y para adelante que son propios de toda evolución.

En suma, el derecho igualitario, culminación de la evolución derecho machista / derecho masculino / derecho igualitario, es, aún hoy en día, un desiderátum a alcanzar más que una realidad. Y las leyes de igualdad modernas nos ponen en el buen camino.

\section{La evolución en España desde la constitución de 1978 hasta nuestros días}

\subsection{Situación normativa anterior (1939-1975)}

Antes de la Constitución de 1978, el ordenamiento jurídico español se debía catalogar como patriarcal fuerte. Y es que hasta la Guerra Civil (1936-1939), España había seguido, con cierto retraso pero no tan de lejos, los avances en materia de igualdad del resto de los países occidentales, estando reconocidos en nuestro ordenamiento el derecho a la educación desde 1912 y el derecho al voto desde 1931. Pero tras la finalización de la Guerra Civil, se produjo, al instaurarse un régimen de confesa inspiración paternalista ${ }^{2}$, un descuelgue respecto a la evolución acaecida en los demás países occidentales, e incluso se dieron pasos atrás en relación con la legalidad anterior, reforzando la normativa laboral proteccionista, retrocediendo en el estatus familiar de las mujeres y retomando con fuerza el principio de educación utilitarista de las mujeres (es decir, dirigida a desarrollar las labores domésticas y de cuidado).

El Código Penal de 1944, seguía a la perfección el guion patriarcal / paternalista, protegiendo las ideas políticas, religiosas y sociales imperantes. Así, se castigaba el adulterio de la mujer, pero el del marido solo con amancebamiento entendido como

\footnotetext{
${ }^{2}$ Como lo demuestran los discursos de Pilar Primo de Rivera, que fue la líder de la Sección Femenina de la Falange Española, afirmando que "el verdadero deber de las mujeres para con la Patria es formar familias con una base exacta de austeridad y de alegría en donde se fomente todo lo tradicional -lo que no haremos nunca es ponerlas en competencia con ellos porque jamás llegarán a igualarlos y en cambio perderían toda la elegancia y toda la gracia indispensable para la convivencia" (1938), que "las Secciones Femeninas respecto a sus jefes tienen que tener una actitud de obediencia y subordinación absoluta-como es siempre el papel de la mujer en la vida, de sumisión al hombre" (1941), o que "las mujeres nunca descubren nada, les falta el talento creador, reservado por Dios para las inteligencias varoniles" (1943). Juana María GIL RUÍZ analiza el paralelismo con el fascismo italiano en Las políticas de igualdad en España: avances y retrocesos, Universidad de Granada (Granada, 1996), pp. 140-147.

IQUAL. REVISTA DE GÉNERO E IGUALDAD, 2022, 5, 1-27

ISSN. 2603-851X

DOI. http://dx.doi.org/10.6018/iqual.498191
} 
relación estable con concubina dentro de la casa conyugal o notoriamente fuera de ella, o se castigaba como falta el maltrato verbal de la mujer al marido, pero no el del marido a la mujer, amparando el derecho de corrección verbal del marido a la mujer. Pero el "ranking del paroxismo patriarcal" lo ocupaba el uxoricidio honoris causa (el conocido en el foro como delito calderoniano), que cuasi exculpaba al marido que, sorprendiendo en adulterio a su mujer, matase o lesionase en el mismo acto a un adúltero o a ambos3.

El Código Civil contenía numerosas normas discriminatorias: el adulterio de la mujer era causa de separación mientras el del marido solo si mediaba escándalo público o menosprecio de la mujer, lo cual se justificaba en la distinta condición del hijo adulterino del padre o de la madre y en una supuesta diversidad psíquica del hombre; la viuda bínuba perdía la patria potestad sobre sus hijos, salvo disposición testamentaria del padre difunto; la mujer no podía ser testigo testamentario u ocupar cargos tutelares; se le prohibía abandonar el hogar familiar antes de los 25 años sin la autorización de su padre o de su madre; y se mantenía en el matrimonio el sistema de potestad marital4.

$Y$, en el ámbito laboral5, el paternalismo del Régimen franquista lo plasmaba a la perfección el Fuero del Trabajo (1928) al establecer que el Estado "prohibirá el trabajo nocturno de las mujeres ... (y) liberará a la mujer casada del taller y de la fábrica". Por su lado, el Decreto de 26 de julio de 1957 del Ministerio de Trabajo, recopiló, en un largo Anexo, los trabajos prohibidos a las mujeres con justificación de la prohibición, donde, a título de ejemplos llamativos, se enumeraban los trabajos con animales feroces o venenosos, por existir peligro de accidentes, en pompas fúnebres, por trabajo penoso, o la conducción de vehículos de tracción animal o mecánica, por peligro de accidentes.

\footnotetext{
${ }^{3}$ Según el artículo 428 del Código Penal de 1944, "el marido que sorprendiendo en adulterio a su mujer, matase en el acto a los adúlteros o a alguno de ellos, o les causase cualesquiera de las lesiones graves, será castigado con la pena de destierro. Si les causase lesiones de otra clase, quedará exento de pena. Estas reglas son aplicables, en análogas circunstancias, a los padres respecto de sus hijas menores de veintitrés años y sus corruptores, mientras aquellas viviesen en la casa paterna". Ramón GARCÍA ALBERO es quien utiliza la afortunada expresión de "ranking del paroxismo patriarcal", en "Las perspectivas de género en Derecho Penal: algunas reflexiones", en el libro colectivo, dirigido por Ángeles VIVAS LARRUY, La discriminación por razón de sexo tras 25 años de la Constitución española, Cuadernos de Derecho Judicial III/ 2004, CGPJ (Madrid, 2004), página 463. Sobre la plasmación de la ideología patriarcal en las resoluciones judiciales de la época, resulta de interés el libro de Juan José RUÍZ-RICO LÓPEZ-LENDÍNEZ, El sexo de Sus Señorías, Ediciones Temas de Hoy (Madrid, 1991).

${ }_{4}^{4}$ Aunque en aquella época histórica las diferencias por sexo eran muchas en el Código Civil, más trascedentes aún eran las diferencias por matrimonio, las cuales suponían "la implantación de un status: jefe-marido frente a subordinada-mujer; dato del cual derivará una vejación jurídica generalizada de la mujer", como afirma Ángel Manuel LÓPEZ Y LÓPEZ, "Diversidad, feminismo y principio de igualdad", en la obra colectiva coordinada por Laura LÓPEZ DE LA CRUZ / Marta OTERO CRESPO, y dirigida por María Paz GARCÍA RUBIO / María del Rosario VALPUESTA FERNÁNDEZ, El levantamiento del velo: Las mujeres en el Derecho Privado, Editorial Tirant lo Blanch (Valencia, 2011), página 24.

${ }^{5}$ Acerca de la normativa laboral franquista, Josefa Dolores RUÍZ RESA, Trabajo y Franquismo, Editorial Comares (Granada, 2000), pp. 138 a 145, y la serie de María Jesús ESPUNY I TOMÁS, "Aproximación histórica al principio de igualdad de género: (I) Propósitos y realidades en la II República Española. (II) EI femenino después de la Guerra. (III) Las Reglamentaciones de Trabajo, observatorios de la desigualdad. (IV) De la Ley de Contrato de Trabajo de 1944 a las últimas disposiciones franquistas", Iuslabor, números 3/2006, 1/2007, 2/2007 y 1/2008, accesibles desde www.dialnet.unirioja.es.

IQUAL. REVISTA DE GÉNERO E IGUALDAD, 2022, 5, 1-27 
Iniciado el segundo franquismo, caracterizado por la apertura internacional y la política económica desarrollista, se produjeron algunos cambios. Así la Ley de 24 de abril de 1958, que reformó el Código Civil, derogó alguna prohibición aplicable a las mujeres (como la de ser testigo testamentario u ocupar cargos tutelares), aunque ratificaba que, "por exigencias de la unidad matrimonial, existe una potestad de dirección que la Naturaleza, la Religión y la Historia atribuyen al marido". Y la Ley 56/1961, de 22 de julio, de derechos políticos, profesionales y de trabajo de la mujer, contenía una cláusula general de igualdad, aunque mantuvo las prohibiciones de trabajo y, en particular, el acceso a la judicatura con carácter general, a la fiscalía y al ejército ${ }^{6}$.

Tal línea de tímidos avances se acentúa, dentro de un también tímido aperturismo, en las postrimerías del Régimen franquista, siendo los siguientes los más llamativos: (1) el Decreto 168/1963, de 24 de enero, Texto revisado del Código Penal, derogó el uxoricidio honoris causa, (2) la Ley 96/1966, de 28 de diciembre, derogó la prohibición de acceso a la judicatura y a la fiscalía, (3) el Decreto 2310/1970, de 20 de agosto, sobre derechos laborales de la mujer, introdujo derechos de conciliación de titularidad femenina como la excedencia voluntaria para el cuidado de hijos/as, y (4) la Ley de 2 de mayo de 1975, modificativa del Código Civil, reconoció capacidad de obrar a la esposa al derogar la licencia marital, necesaria entre otras cosas para poder trabajar.

A la altura de 1975, se mantenía así, con algunos retoques, el patriarcado paternalista, y es entonces cuando empieza a periclitar simultáneamente a la implantación de un Régimen democrático, y si consideramos nuestra situación actual, es evidente lo vertiginoso del cambio normativo acaecido. $Y$ como revulsivo coyuntural actuó el que la ONU lo había declarado Año Internacional de la Mujer, celebrándose reuniones, jornadas y congresos con la consiguiente visibilización del movimiento feminista, siendo en la Transición cuando se produjo la disensión (no superada aún del todo) entre feministas independientes y feministas vinculadas a partidos de izquierdas que ha marcado la evolución posterior de todo el movimiento feminista en España7.

\subsection{El cambio constitucional (1978)}

La Constitución de 1978 reintroduce con fuerza la igualdad, ya que, además de enunciarla (junto con libertad, justicia y pluralismo político) entre los valores superiores del ordenamiento jurídico español (artículo 1.1), se establece que "los españoles son iguales ante la ley, sin que pueda prevalecer discriminación alguna por razón de nacimiento, raza, sexo, religión, opinión o cualquier otra condición o circunstancia

\footnotetext{
${ }^{6}$ Sobre esta concreta norma, Manuel ALONSO OLEA, "La Ley del 24 de julio de 1961 sobre derechos políticos, profesionales y de trabajo de la mujer", Revista de la Administración Pública, número 36, 1961. ${ }_{7}$ Sobre la evolución del feminismo español, Asunción VENTURA FRANCH, Las mujeres y la Constitución Española de 1978, Instituto de la Mujer (Madrid, 1999), pp. 89 a 119, y Juan Sinisio PÉREZ GARZÓN, Historia del feminismo, Los Libros de la Catarata (Madrid, 2011), pp. 235 a 244.

IQUAL. REVISTA DE GÉNERO E IGUALDAD, 2022, 5, 1-27

ISSN. 2603-851X

DOI. http://dx.doi.org/10.6018/iqual.498191
} 
personal o social" (artículo 14), completándose con un mandato a los Poderes Públicos de "promover las condiciones para que la libertad y la igualdad del individuo y de los grupos en que se integra sean reales y efectivas" (artículo 9.2), aparte de hasta otras diez referencias a la igualdad en los artículos 23.2 (acceso en igualdad a funciones y cargos públicos), 31.1 (sistema tributario justo basado en los principios de igualdad y progresividad), 32.1 (igualdad de hombres y mujeres en el matrimonio) ${ }^{8}$, 35.1 (no discriminación sexista en derechos laborales) ${ }^{9}, 39.2$ (igualdad de los hijos ante la ley con independencia de su filiación), 68.1 (sufragio universal, libre, igual, directo y secreto para elegir a los miembros del Congreso de los Diputados), 69.2 (ídem para elegir a los miembros del Senado), 139.1 (igualdad de derechos y obligaciones de todos los españoles en cualquier parte del territorio), 140 (sufragio universal, libre, igual, directo y secreto para elegir a los Concejales de los Ayuntamientos) y 149.1.10 (competencia estatal exclusiva para regular las condiciones básicas que garanticen la igualdad de todos los españoles en el ejercicio de los derechos y en el cumplimiento de los deberes constitucionales). Un total de 13 referencias constitucionales a la igualdad.

Únicamente se mantiene una excepción a la igualdad de los sexos en la sucesión a la Corona (artículo 57) ${ }^{10}$, y en la significativa redacción sexuada de la prohibición de asumir funciones constitucionales aplicable a quien se case con la persona titular de la Corona: "la Reina consorte o el consorte de la Reina" (artículo 58), donde ha pesado la concepción de inferioridad social de la mujer porque atribuir al consorte de la Reina el título de Rey eclipsaría el papel de la Reina, mientras que no ocurre así a la viceversa ${ }^{11}$.

Con el amplio reconocimiento del principio de igualdad de los sexos en la Constitución de 1978, se dictaba la sentencia de muerte del paternalismo franquista y se abría la transición del derecho machista al derecho masculino, lo que supuso grandes avances aunque que con las carencias propias de los ordenamientos patriarcales moderados, y tanto los avances como las carencias se pueden comprobar en los cambios legislativos acaecidos en nuestros textos normativos básicos, así como en la interpretación ofrecida en estos primeros años de rodaje por el Tribunal Constitucional.

El Código Penal (no en vano llamado la Constitución negativa de los Estados, y, de hecho, algunas de las reformas a que se aludirá fueron fruto, como la Constitución, de los Pactos de la Moncloa) se sometió a reformas como la Ley 22/1978, de 26 de mayo,

\footnotetext{
${ }^{8}$ Se trata de una "reiteración de la igualdad (con) una especial voluntad igualatoria en la medida en que se refiere a un espacio, el matrimonio, la familia... donde tradicionalmente se ha consolidado la sumisión al orden patriarcal", véase Asunción VENTURA FRANCH, Las mujeres ..., obra citada, pp. 132 y 133.

9 Se trata (como ocurre con el artículo 32.1) de una norma en la cual "el constituyente... reitera la prohibición del artículo 14 de la $C E$, por entender que este es un ámbito especialmente discriminatorio para las mujeres", véase Asunción VENTURA FRANCH, Las mujeres ..., obra citada, pp. 133 y 134.

10 Pilar MELLADO PRADO y Yolanda GÓMEZ SÁNCHEZ sostuvieron su inconstitucionalidad amparándose en que, según la doctrina alemana, son inconstitucionales normas constitucionales contradictorias con otras con un valor superior, "En torno a la posible inconstitucionalidad del apartado 1 del artículo 57 de la Constitución Española de 1978", Revista de Derecho Político, número 22, 1986.

${ }^{11}$ En este sentido, Asunción VENTURA FRANCH, Las mujeres ..., obra citada, pp. 136 y 137. 
sobre despenalización del adulterio y del amancebamiento, y las Leyes 45 y 46/1978, de 7 de octubre, la primera despenalizó la expedición de anticonceptivos, y la segunda derogó el rapto consentido, eliminó el incesto como delito autónomo, y suprimió las exigencias de honestidad de la mujer para ser víctima del estupro. Pero aún eran insuficientes, y así, por ejemplo, no es hasta la Ley Orgánica 8/1983, de 25 de junio, que se eliminan las diferencias según el sexo en la falta de malos tratos verbales.

La Ley 8/1980, de 10 de marzo, del Estatuto de los Trabajadores, reconoció, dentro del planteamiento de igualdad formal propio del patriarcado moderado, el derecho a la no discriminación por razón de sexo en general (artículos 4.2.d) y 17) y en el ámbito de la remuneración (artículo 28), si bien no contenía remedios jurídicos efectivos (ni se contenían en la ley procesal laboral) y presentaba defectos tan importantes como la declaración de igualdad salarial (no retribuciones extrasalariales) por trabajo igual (no por trabajo de igual valor), o la ausencia de una derogación expresa de las prohibiciones de trabajo paternalistas, e incluso se mantenía un vestigio de clara inspiración paternalista como la titularidad femenina única del permiso de lactancia ${ }^{12}$.

También se reformó el Código Civil a través de la Ley 11/1981, de 13 de mayo, en materia de filiación, patria potestad y régimen económico del matrimonio, que introdujo la igualdad de los hijos al margen de su filiación matrimonial o extramatrimonial, que sustituyó la patria potestad paterna sobre los hijos por la patria potestad conjunta, que equiparó a los cónyuges en orden a sus facultades de administración, disposición y endeudamiento de los bienes gananciales, y que suprimió la regulación específica de la dote de la mujer y de sus bienes parafernales, y a través de la Ley 30/1981, de 7 de julio, en materia de regulación del matrimonio, que es conocida como la ley de divorcio pues reguló las causas de nulidad, separación y divorcio ${ }^{13}$.

Acorde con la concepción de las leyes de igualdad modernas, indiferentes al género y en desconocedoras de cuál es el sexo social y culturalmente discriminado, el Tribunal Constitucional, en sus primeras aplicaciones del artículo 14 de la $C E$, acogió una rígida interpretación sex-blind (es decir construida sobre la indiferencia del sexo, como si no

\footnotetext{
${ }^{12}$ El planteamiento del Estatuto de los Trabajadores lo criticó duramente Teresa PÉREZ DEL RíO porque "desde la óptica de igualdad esencial (contiene) una serie de disposiciones aisladas y de principio ... (que) reconocen derechos pero no articulan procedimientos específicos para su ejercicio, lo que, en la práctica, se traduce en una inefectividad total de este reconocimiento, dada la dificultad de actuar en el campo concreto de la discriminación por los procedimientos generales... ha sido históricamente demostrada la ineficacia de estas formas de tratamiento general cara a la erradicación de la discriminación por sexo en el trabajo... un tratamiento general e indiscriminado es no solo insuficiente, sino también injusto e inadecuado... el tratamiento específico de situaciones de desigualdad especialmente graves ha sido estimado como acertado y necesario"; María Teresa PÉREZ DEL RÍO, El principio de igualdad: no discriminación por razón de sexo en el Derecho del Trabajo, IELSS (Madrid, 1984), pp. 39 y 40.

${ }^{13}$ Véase Ana Supaya FERNÁNDEZ-SANCHO TAHOCES, "La evolución de la situación de la mujer en el Derecho civil español", pp. 179-203, y Silvia TAMAYO HAYA, "La posición jurídica de la mujer a través de las reformas del Derecho de familia", en El levantamiento ..., obra citada, pp. 759-804.

IQUAL. REVISTA DE GÉNERO E IGUALDAD, 2022, 5, 1-27

ISSN. 2603-851X

DOI. http://dx.doi.org/10.6018/iqual.498191
} 
existieran los prejuicios de género ${ }^{14}$ ), dando lugar a la doctrina del varón discriminado ${ }^{15}$ pues los demandantes eran hombres a quienes se extendían supuestos beneficios femeninos basados en rancios estereotipos paternalistas, ofreciendo así una imagen invertida en la situación real de discriminación de la mujer. Por ejemplo, cuando extiende a los trabajadores varones ventajas retributivas asociadas al trabajo nocturno solo reconocidas a las trabajadoras mujeres con una finalidad protectora. Aunque el caso más conocido es la pensión de viudedad: la legislación española la concedía a los hombres si eran incapaces y a las mujeres siempre pues, basándose en el estereotipo de que el destino de la mujer es ser mantenida por su marido, se establecía una suerte de presunción de incapacidad que le abría el camino a la pensión de viudedad; desde la STC 103/1983, de 22 de noviembre, a los hombres también se les concede siempre.

Por todo ello, la Constitución, interpretada como una ley de igualdad clásica, corría el riesgo de fosilizarse (usando las categorías de Karl Loewenstein) como una constitución semántica (una formalización jurídica de la situación fáctica existente, en este caso de la desigualdad material de los sexos bajo el ropaje de una igualdad formal), sin alcanzar la categoría de constitución normativa (que impone sus mandatos a los poderes fácticos, en este caso a los patriarcales) ${ }^{16}$. Ciertamente, también contiene normas (en particular, su artículo 9.2) que han posibilitado cambios legales y judiciales que han permitido transitar de un derecho masculino a un derecho más igualitario.

\subsection{De la igualdad formal a la igualdad material (1985-1995)}

Aunque en los iniciales momentos el entendimiento del texto constitucional, tanto por la legislación ordinaria como por la jurisprudencia constitucional, se situaba en la filosofía de las leyes de igualdad clásicas y en una concepción formalista de la igualdad de los sexos, la Constitución de 1978 admite otros entendimientos diferentes más comprometidos con la igualdad efectiva de mujeres y hombres, los cuales fueron progresivamente asumidos por la jurisprudencia constitucional y por la legislación

\footnotetext{
14 Usan la expresión "sex-blind", literalmente sexo ciego, Fernando REY MARTíNEZ, El derecho fundamental a no ser discriminado por razón de sexo, Editorial Mc Graw Hill (Madrid, 1995), página 9, Y Andrés OLLERO TASSARA, Discriminación por razón de sexo, CEPC (Madrid, 1999), p. 61.

${ }^{15}$ En la irónica expresión de Manuel ALONSO OLEA, Jurisprudencia constitucional sobre Trabajo y Seguridad Social, Tomos III, IV y V, Editorial Civitas (Madrid, 1985, 1986 y 1987, respectivamente).

${ }^{16}$ La distinción entre constituciones semánticas y normativas en Karl LOEWENSTEIN, Teoría de la Constitución, Ariel Derecho (Barcelona, 1986), pp. 216-217. Trae a colación esta distinción Asunción VENTURA FRANCH, quien tras recordar que, para Karl LOEWENSTEIN, una constitución normativa es "como un traje que sienta bien y que se lleva realmente", añade que "las constituciones tienen un corte de traje sastre tipo caballero que, de entrada, no sienta bien a las mujeres, porque estas tienen formas distintas y en algunas de las etapas, por ejemplo, embarazos, que atraviesa la vida de una mujer es imposible poder vestirse con ese traje", y, yendo más allá en el símil, que "de todas formas, no hay que predeterminar el tipo de vestimenta del que se quieran dotar dos sujetos en igualdad de condiciones, podrá ser igual con cortes diferentes o podrá ser totalmente diferente, será válida cualquier opción siempre que no se trate de una imposición" (Las mujeres ..., obra citada, p. 167).
}

IQUAL. REVISTA DE GÉNERO E IGUALDAD, 2022, 5, 1-27 
ordinaria desde mediados de los años ochenta hasta mediados de los años noventa, un periodo reconocible como la primera década prodigiosa en el avance hacia la igualdad.

La avanzadilla le correspondió al Tribunal Constitucional, que, pasando de una bilateralidad ciega a una preferente unilateralidad a favor de la mujer ${ }^{17}$, cambió radicalmente el rumbo, aunque ese cambio de rumbo, en algunos aspectos bastante sólido (como la discriminación por embarazo o la discriminación sexista indirecta), en otros aspectos fue bastante atormentado (como la acción positiva o el abandono de la igualación por arriba). Con ánimo de apuntar las líneas de tendencia de la jurisprudencia constitucional tras el cambio de rumbo, se deben destacar los siguientes leading-cases:

a) La STC 128/1987, de 16 de julio, donde, a propósito de un plus de guardería para el personal femenino, se negó su extensión al masculino al ser una medida de acción positiva para permitir a las madres conservar su trabajo facilitándoles el cuidado de sus hijos. Aunque el nuevo concepto de acción positiva se ha aplicado en apenas otras dos ocasiones, y en algún caso bajo la sospecha de justificar medidas paternalistas, una para justificar una mayor pensión de jubilación a favor de las mujeres dirigida a compensar sus inferiores condiciones laborales y mantenida transitoriamente (STC 19/1989, de 31 de enero), y otra para justificar una medida tan paternalista como un permiso de lactancia de titularidad solo femenina (STC 109/1993, de 25 de marzo).

b) La STC 166/1998, de 26 de septiembre, consideró discriminación sexista la extinción de un contrato de trabajo durante el periodo de prueba a causa del embarazo (ratificando y aplicando la doctrina obiter dicta de la muy tempranera STC 94/1984, de 16 de octubre), doctrina luego consolidada (SSTC 173/1994, de 7 de junio, 136/1996, de 23 de julio, 20/2001, de 20 de enero, 41/2002, de 25 de febrero, 17/2003, de 30 de enero, $98 / 2003$, de 2 de junio, 161/2004, de 4 de octubre, 175/2005, de 4 de julio, 182/2005, de 4 de julio, 324/2006, de 20 de noviembre, 342/2006, de 11 de diciembre, 17/2007, de 12 de febrero, 62/2007, de 27 de marzo, 74/2008, de 23 de junio, 92/2008, de 21 de julio, 31/2014, de 24 de febrero, 0 108/2019, de 30 de septiembre).

c) La STC 145/1991, de 1 de julio, donde se introdujeron los conceptos de discriminación indirecta y de trabajo de igual valor al considerar discriminatoria una desigualdad salarial de trabajos de igual valor realizados por peones (mayoritariamente hombres) y limpiadores (mayoritariamente mujeres), sentando así una doctrina desarrollada en materia de retribuciones (SSTC 58/1994, de 28 de febrero, 286/1994, de

\footnotetext{
${ }_{17}$ Un cambio de rumbo anunciado por los estudios doctrinales, en especial de la laboralística, sobre la igualdad y la no discriminación a mediados de los años ochenta, como fueron el de Teresa PÉREZ DEL RÍO, El principio .... obra citada, y el de Miguel RODRÍGUEZ-PIÑERO / María Fernanda FERNÁNDEZ LÓPEZ, Igualdad y discriminación, Editorial Tecnos (Madrid, 1986). Ambos destacables por su valía científica, y el segundo además porque Miguel Rodríguez-Piñero fue nombrado Magistrado del Tribunal Constitucional, del cual llegó a ser Presidente, facilitando la recepción de las ideas acerca de la igualdad material. La bibliografía laboralista y constitucionalista sobre este cambio de rumbo es muy abundante. Destacaré al efecto los estudios de Fernando Rey MARTÍNEZ, El derecho ..., obra citada, pp. 9 a 38, y el de Asunción VENTURA FRANCH, Las mujeres ..., obra citada, pp. 192 a 223.

IQUAL. REVISTA DE GÉNERO E IGUALDAD, 2022, 5, 1-27

ISSN. 2603-851X

DOI. http://dx.doi.org/10.6018/iqual.498191
} 
27 de octubre, 147/1995, de 16 de octubre, y 250/2000, de 30 de noviembre), acceso al empleo (STC 41/1999, de 22 de marzo), conciliación (SSTC 240/1999, de 20 de diciembre, 203/2000, de 24 de julio, y 3/2007, de 15 de enero), y Seguridad Social (SSTC 253/2004, de 22 de diciembre, 61/2013, de 14 marzo, y 91/2019, de 3 julio).

d) La STC 216/1991, de 14 de noviembre, que consideró discriminatoria la inadmisión de una mujer como piloto en la Academia General del Aire, y, sobre todo, la STC 229/1992, de 14 de diciembre, que consideró discriminatoria la prohibición de trabajo de las mujeres en el interior de las minas, fueron la sentencia de muerte del paternalismo, cuyo arrumbamiento definitivo supuso (1) el abandono, tras un periodo de cierta desorientación, de la igualación por arriba (STC 28/1992, de 9 de marzo, STC 315/1994, de 28 de noviembre, y STC 16/1995, de 24 de enero), y (2) la derogación de los beneficios paternalistas, debiéndose denegar aún si los pide una mujer como ocurrió con una dote establecida en convenio colectivo (STC 317/1994, de 28 de noviembre).

Con el trasfondo de la evolución de la jurisprudencia constitucional (y también con el trasfondo de la entrada de España en la Comunidad Económica Europea, 1986), el Instituto de la Mujer, creado en la Ley 16/1983, de 24 de octubre, impulsó una serie de reformas legislativas de importante calado en la misma línea de tendencia de pasar de una igualdad formal a una igualdad material. En el ámbito penal, la Ley Orgánica 3/1989, de 21 de julio, modificó varios artículos del Código Penal para equiparar la penetración anal y oral a la vaginal a efectos del delito de violación, o para introducir los delitos de impago de pensiones y (con una tipificación todavía muy imperfecta desde la óptica de su efectividad práctica) de malos tratos familiares ${ }^{18}$. En el ámbito civil, la Ley 11/1990, de 15 de octubre, modificó varios artículos del Código Civil para eliminar los vestigios del sistema de jefatura marital, igualar al padre en la custodia de los hijos, redefinir la intimidación y otras varias modificaciones menores. En el ámbito social, la reforma estrella fue la Ley 3/1989, de 3 de marzo, que amplió a 16 semanas el permiso por maternidad y que establece medidas para favorecer la igualdad de trato de la mujer en el trabajo, entre ellas se introdujo el disfrute paterno de la licencia de maternidad en los casos de fallecimiento y de cesión de la madre, y el disfrute paterno del permiso de lactancia (aunque siendo de titularidad femenina), se mejoró la reducción de jornada y la excedencia para el cuidado de hijos/as, y se contempló la protección frente al acoso sexual laboral. Por otro lado, la Ley 26/1990, de prestaciones no contributivas, eliminó discriminaciones directas subsistentes en la Seguridad Social.

Utilizando esa técnica de establecer mejoras en materia de igualdad a través de otras leyes, las canalizadoras de la Reforma Laboral de 1994 mejoraron el enunciado legal de la igualdad salarial, sustituyendo el enunciado igual salario por igual trabajo por el enunciado igual salario por trabajo de igual valor (artículo 28 del ET, según la Ley

\footnotetext{
${ }^{18}$ Así es que en 1989 se superó "el Derecho Penal simplemente discriminatorio", quedando solo "un Derecho Penal masculino" (Ramón GARCÍA ALBERO, "Las perspectivas ...", obra citada, p. 465).

IQUAL. REVISTA DE GÉNERO E IGUALDAD, 2022, 5, 1-27 
11/1994, de 19 de mayo), desvinculando el subsidio de maternidad del subsidio de incapacidad temporal y elevándolo al 100\% (Ley 42/1994, de 30 de diciembre), y reforzando la excedencia para cuidado de hijos para atribuirle las notas más garantistas de la excedencia forzosa (artículo 46.3 del ET, según la Ley 4/1995, de 23 de marzo). Pero a la Reforma Laboral de 1994 le faltaba una visión transversal, de donde esas mejoras quedaron diluidas por el efecto perjudicial de otras reformas, como la potenciación de los niveles negociales inferiores donde aparecen con más frecuencia cláusulas discriminatorias y donde las medidas de acción positiva o igualdad de oportunidades son infrecuentes ${ }^{19}$, o la reducción de la protección social del feminizado trabajo a tiempo parcial a través de la infraprotección del trabajo de escasa jornada (que se mantuvo vigente hasta el Real Decreto Ley 8/1997, de 16 de mayo), y del cómputo perjudicial de carencias en el trabajo a tiempo parcial (que solamente en parte corrigió el Real Decreto Ley 15/1998, de 27 de noviembre, igualmente discriminatorio) ${ }^{20}$.

\subsection{Hacía la igualdad de género (2000-2010)}

Bajo el empuje de la IV Conferencia Mundial sobre las Mujeres de Beijing (1995), será, en los años siguientes, cuando, a partir de finales de los años noventa y hasta la llegada de la Gran Crisis (una segunda década prodigiosa), se abre una etapa de leyes con perspectiva de género, primero en las formas luego también en el contenido.

La Ley 39/1999, de 5 de noviembre, para promover la conciliación de la vida familiar y laboral de las personas trabajadoras, presenta la forma de las leyes transversales, al afectar a numerosos sectores del ordenamiento jurídico, pero en cuanto al contenido se queda muy corta en su apuesta por la corresponsabilidad y la conciliación masculina, con lo cual, siendo una norma con avances significativos, en muchos aspectos seguía lastrada en planteamientos de las leyes de igualdad clásicas ${ }^{21}$.

También en estos años se aprueba la Ley 33/2002, de 5 de julio, que modifica el artículo 28 del ET para aclarar que el trabajo de igual valor obliga, no solo a un igual salario, también a una igual retribución, incluyendo pues percepciones extrasalariales.

\footnotetext{
${ }^{19} \mathrm{Y}$ ello incrementa el riesgo de desigualdades retributivas, véase Beatriz OUINTANILLA NAVARRO, "Igualdad de retribución por razón de sexo", en la obra colectiva dirigida por Fernando VALDÉS DAL RÉ, La reforma del mercado Laboral, Editorial Lex Nova (Valladolid, 1994), pp. 231 a 235.

${ }^{20}$ Véase José Fernando LOUSADA AROCHENA, "El cómputo de la carencia para las prestaciones de seguridad social en los contratos de trabajo a tiempo parcial", Poder Judicial, 43/44, 1996.

${ }^{21}$ Ver las críticas de María Amparo BALLESTER PASTOR, que se podrían resumir en dos grandes ideas centrales: no se introducen auténticos mecanismos de corresponsabilidad, aunque se corrigen algunos defectos puntuales para la conciliación masculina; y no se acomete un tratamiento unitario y extenso de los derechos de conciliación, limitándose la norma a los temas más clásicos de la conciliación, La Ley 39/1999 de conciliación de la vida familiar y laboral: Una corrección de errores con diez años de retraso, Editorial Tirant lo Blanch (Valencia, 2000). Parecidamente, Laura MORA CABELLO DE ALBA afirma que la Ley "no cuestionó el modo de dominación masculino de relación entre los sexos", aunque reconoce que "hizo público un asunto que muchos creen que es un tema estrictamente privado", "Del malabarismo cotidiano a una nueva civilización más allá de la igualdad. La reconciliación de la vida laboral y familiar", Revista de Derecho Social, número 37, 2007, pp. 132 y 133, passim.

IQUAL. REVISTA DE GÉNERO E IGUALDAD, 2022, 5, 1-27

ISSN. 2603-851X

DOI. http://dx.doi.org/10.6018/iqual.498191
} 
La Ley 30/2003, de 13 de octubre, sobre medidas para incorporar la valoración del impacto de género en las disposiciones normativas que elabore el Gobierno, impone un informe de impacto de género en la elaboración de leyes y reglamentos, lo que, aunque aparenta poca cosa, ostenta, si se aplica bien, un potencial transformador ilimitado. A esta Ley le corresponde el mérito de ser la primera ley estatal declaradamente transversal. Su Exposición de Motivos alude al "principio de transversalidad" y a "la Cuarta Conferencia Mundial sobre la Mujer que tuvo lugar en Pekín (Beijing) 1995", y se utiliza de manera precisa y correcta el concepto "género" ${ }^{22}$.

En la siguiente legislatura es cuando se producen los mayores avances en orden a introducir leyes de igualdad modernas dirigidas a erradicar de manera transversal los estereotipos de género, y en particular, las dos leyes que constituyen el centro neurálgico del conjunto normativo: la ley de violencia de género y la ley de igualdad.

Cronológicamente, la primera de esas dos leyes es la Ley Orgánica 1/2004, de 28 de diciembre, de Medidas de Protección Integral contra la Violencia de Género. Su objeto es "actuar contra la violencia que, como manifestación de la discriminación, la situación de desigualdad y las relaciones de poder de los hombres sobre las mujeres, se ejerce sobre estas por parte de quienes sean o hayan sido sus cónyuges o de quienes estén o hayan estado ligados a ellas por relaciones similares de afectividad, aun sin convivencia" (artículo 1): una definición donde claramente aparece el elemento de dominación / subordinación característico de las teorizaciones feministas sobre el género; aunque con el inconveniente de que solo se proyecta en las relaciones de pareja, o ex pareja, olvidando la existencia de otras violencias de género. Se trata de una ley transversal tanto por las formas, afectando a numerosos sectores del ordenamiento jurídico, como por los contenidos, buscando erradicar los prejuicios de género, y reconociendo la transversalidad de la igualdad de género como un principio inspirador.

La segunda de esas dos leyes es la Ley Orgánica 3/2007, de 22 de marzo, para la Igualdad Efectiva de Mujeres y Hombres. Aquí se encuentra lo que podríamos denominar la parte general del derecho a la igualdad en nuestro ordenamiento jurídico en cuanto define los conceptos básicos y establece mecanismos de efectividad. Se trata de una ley de igualdad moderna, o sea decididamente transversal y comprometida con la igualdad material, como expresamente se deduce de su Exposición de Motivos: "el pleno reconocimiento de la igualdad formal ante la ley, aun habiendo comportado, sin duda, un paso decisivo, ha resultado ser insuficiente"; "la mayor novedad de esta Ley radica ... en la prevención de (las) conductas discriminatorias y en la previsión de

${ }^{22}$ Comentarios de la Ley $30 / 2003$, en su momento, el de Miguel RODRíGUEZ-PIÑERO Y BRAVOFERRER, "El informe sobre el impacto por razón de género en la elaboración de las disposiciones normativas", Relaciones Laborales, número 1, 2004, pp. 117-128, y el de José Fernando LOUSADA AROCHENA "El informe sobre el impacto de género en la elaboración normativa", Aequalitas: Revista jurídica de igualdad de oportunidades entre mujeres y hombres, número 15, 2004, pp. 39 a 46. 
políticas activas para hacer efectivo el principio de igualdad", "la consideración de la dimensión transversal de la igualdad, seña de identidad del moderno derecho antidiscriminatorio, (es) principio fundamental del presente texto"; "la Ley nace con la vocación de convertirse en la ley - código de la igualdad entre mujeres y hombres".

Tal configuración como ley de igualdad moderna se ratifica en su articulado (estructurado en 78 artículos, 31 disposiciones adicionales, 11 disposiciones transitorias, 1 disposición derogatoria y 8 disposiciones finales) a través de lo siguientes rasgos:

(1) La consideración de la igualdad, no solo como un valor fundamental o como un principio (que es como la califica la CE, artículos 1 y 14), sino también como un "derecho de igualdad de trato y oportunidades entre mujeres y hombres" (artículo 1), con amplios contenidos, titularidad general, universalidad objetiva, eficacia entre privados, aplicación territorial, vocación de eficacia (artículos 2 y 3). A tal dimensión subjetiva del derecho, la ley de igualdad le aúna explícitamente la dimensión objetiva o institucional que caracteriza a todo derecho fundamental, según la cual "la igualdad de trato y de oportunidades entre mujeres y hombres es un principio informador del ordenamiento jurídico y, como tal, se integrará y observará en la interpretación y aplicación de las normas jurídicas" (artículo 4), disposición central en la arquitectura legal que ha posibilitado la normalización del enjuiciamiento con perspectiva de género.

(2) La recepción mejorada de los conceptos recogidos en las normas comunitarias relativos a la buena fe ocupacional (artículo 5), discriminación directa e indirecta (artículo 6), acoso sexual y sexista (artículo 7), o prueba de la discriminación (artículo 13). Las mejoras son varias, y muy significativas. Por ejemplo, se elimina el calificativo "indeseado" del concepto de acoso sexual y sexista en el convencimiento de que lo que es ofensivo es, como norma general, indeseado, o se califica como discriminación directa todo trato desfavorable a las mujeres relacionado con el embarazo o la maternidad (artículo 8), o se considera sexista la discriminación basada en el ejercicio de derechos de conciliación, incluso ejercitados por varones (artículo 44).

(3) La plasmación del principio de transversalidad de igualdad de trato y oportunidades entre mujeres y hombres como informador, con carácter transversal, de la actuación de todos los Poderes Públicos (artículo 15), especificándose los criterios de actuación que garantizarán esa transversalidad (artículo 14), así como las estrategias (inspiradas en la Declaración de Beijing y en la Plataforma para la Acción de la IV Conferencia Mundial de las Mujeres, 1995) dirigidas a implementarla: planes públicos de igualdad (artículo 17); informes de impacto de género (artículo 19); estadísticas desagregadas por sexo (artículo 20); colaboración entre las administraciones públicas (artículo 21). Dentro de estas estrategias características de la transversalidad, aplicadas al sector privado, se inscriben los planes de igualdad (artículos 45 a 49), la igualdad en el acceso a bienes o servicios (artículos 69 a 72), y la responsabilidad social de empresas y el empoderamiento de mujeres en sus órganos directivos (artículo 73 a 75). 
(4) La universalidad objetiva supone integrar la igualdad en todas las políticas públicas, y, en particular, en materia de educación (artículos 23 a 25), producción artística e intelectual (artículo 26), salud pública (artículo 27), sociedad de la información (artículo 28), deportes (artículo 29), política rural (artículo 30), urbanismo (artículo 31), o cooperación al desarrollo (artículo 32); como medida complementaria, se impone la formación de quienes se dedican al servicio público (artículo 61). En esta misma línea de universalidad, se revisa en profundidad la legislación laboral, funcionarial y de protección social al extremo de que, cuantitativamente, es el grueso normativo de la ley de igualdad (disposiciones adicionales, de la $11^{\mathrm{a}}$ a la $24^{\mathrm{a}}$ ).

(5) La cobertura normativa de las acciones positivas (artículo 11), habilitando su canalización a través de preferencias en la contratación administrativa (artículo 33 y 34 ), subvenciones públicas (artículo 35), apoyo para planes voluntarios de igualdad en las empresas (artículo 49), o el establecimiento del distintivo de igualdad (artículo 50).

(6) La implantación de mecanismos dirigidos a la consecución de una democracia paritaria, obligando a una presencia o composición equilibrada de ambos sexos (cuantificada en un 40/60) en las listas electorales de partidos políticos (disp. ad. $2^{a}$ ), en los órganos discrecionales nombrados por la Administración General del Estado (artículos 52 a 54), y en todos los nombramientos de los cargos públicos (artículo 16).

Otras leyes con evidente perspectiva de género en este periodo son la Ley 9/2005, de 6 junio, para compatibilizar las pensiones del Seguro Obligatorio de Vejez e Invalidez con las pensiones de viudedad del Sistema de la Seguridad Social (la incompatibilidad vigente perjudicaba a viudas con escasos recursos económicos), la Ley Orgánica 3/2005, de 8 julio, para perseguir extraterritorialmente la práctica de la mutilación genital femenina, la Ley 33/2006, de 30 octubre, de igualdad del hombre y la mujer en el orden de sucesión de los títulos nobiliarios, o la Ley Orgánica 2/2010, de 3 marzo, de salud sexual y reproductiva y de interrupción voluntaria del embarazo.

Una aclaración final se impone. $Y$ es la de que el Tribunal Constitucional ha declarado la constitucionalidad de las nuevas leyes de igualdad ${ }^{23}$. La STC 12/2008, de 29 de enero, ha declarado, con base en la igualdad sustancial del artículo 9.2 de la CE, la constitucionalidad de las (mal) llamadas cuotas electorales (pues no son una acción

\footnotetext{
${ }^{23}$ María Luisa BALAGUER CALLEJÓN, después de analizar la legislación dictada en materia de género y la jurisprudencia constitucional referida a esa legislación, concluye, por un lado, que "la legislación que se ha producido en materia de género, conlleva un cambio radical de concepción del modelo de vida, de distribución de roles y pautas sociales, políticas y económicas, y en definitiva de revolución social... cambio (que) deberá producirse progresivamente en función del desarrollo que estas normas están produciendo, tanto en el ámbito estatal como en los ordenamientos autonómicos... el mayor avance histórico que presenta el derecho de igualdad solo comparable al reconocimiento de la igualdad formal que tuvo lugar en el Siglo XVIII con la Revolución francesa", y, por otro lado, que "la inequívoca posición del TC, validando cada una de estas leyes, ha sido decisiva para el avance de los derechos de igualdad de género", Igualdad y Constitución Española, Editorial Tecnos (Madrid, 2010), p. 190.

IQUAL. REVISTA DE GÉNERO E IGUALDAD, 2022, 5, 1-27 
positiva, sino una consecuencia de la democracia paritaria ${ }^{24}$. Igualmente, la STC 59/2008, de 14 de mayo ${ }^{25}$, ha declarado la constitucionalidad de las diferencias penales introducidas en la LOPIVG argumentando al respecto (1) que no se vulnera el principio de igualdad con la mayor punibilidad de la agresión cometida por el hombre contra su pareja o ex pareja atendiendo a la legitimidad de la finalidad de erradicación de la violencia de género, a la funcionalidad de esa mayor punibilidad para conseguir esa finalidad y a la ausencia de desproporción al no ser tan elevada esa mayor punibilidad, y (2) que no se vulnera el principio de culpabilidad porque el hombre que agrede a su pareja o ex pareja inscribe voluntariamente su actuar en una concreta estructura social.

Otras dos sentencias debemos resaltar. LaSTC 3/2007, de 15 de enero, que concede amparo a una trabajadora solicitante de una reducción de jornada haciendo una interesante conexión entre el artículo 39 de la CE (protección de la familia) y el 14 (en su vertiente de discriminación indirecta al ser las mujeres las implicadas en el cuidado de hijos/as) ${ }^{26}$. Y la STC 92/2008, de 21 de julio, que ha estimado la aplicación automática

\footnotetext{
${ }^{24}$ Véase José Fernando LOUSADA AROCHENA, "Unos apuntes sobre las llamadas cuotas electorales a la vista de la decisión de su constitucionalidad", Diario La Ley, núm. 6918, 2008. Sin embargo, la STC 13/2009, de 19 de enero, sobre la ley electoral vasca, que garantiza una representación femenina mínima del 50\% mientras la masculina es del 40\%, y la STC 40/2011, de 31 de marzo, sobre la ley electoral andaluza, que establece las listas cremallera con alternancia de hombres y mujeres, afirman ambas que es "solo constitucionalmente aceptable en tanto que coyuntural". Con lo cual ello aparenta la vuelta al argumentario propio de la acción positiva y un cierto abandono del concepto de democracia paritaria.

${ }^{25}$ La STC 59/2008, de 14 de mayo, se refiere a una cuestión de constitucionalidad sobre el artículo 153.1 del Código Penal, que castiga a "el que por cualquier medio o procedimiento causare... menoscabo psíquico o una lesión no definidos como delito en este Código, o golpeare o maltratare de obra... sin causarle lesión... a quien sea o haya sido esposa, o mujer que esté o haya estado ligado a él por una análoga relación de afectividad, aún sin convivencia". También se plantearon cuestiones de constitucionalidad en relación con el artículo 171.4 del Código Penal, que castiga a "el que de modo leve amenace a quien sea o haya sido su esposa, o mujer que esté o haya estado ligado a él por una análoga relación de afectividad aún sin convivencia". Su resolución se acometió en la STC 45/2009, de 19 de febrero, que siguió de una manera sustancial los mismos argumentos jurídicos que la opinión mayoritaria expresada en la STC 59/2008, de 14 de mayo, y asimismo contiene unos votos particulares semejantes.

${ }^{26} \mathrm{Al}$ conectar la protección de la familia (artículo 39.2 de la CE) con la prohibición de discriminación sexista indirecta (artículo 14 de la CE), el ejercicio de los derechos de conciliación es fiscalizable a través del recurso de amparo constitucional. Pero la discriminación sexista se califica de indirecta, lo que, sin ser incorrecto (porque las mujeres son quienes habitualmente usan los derechos de conciliación), no responde de una manera exacta a un preciso análisis de género, que llevaría a considerarla discriminación directa (porque la discriminación está en perjudicar a quienes asumen roles feminizados, como el cuidado de hijos/as). No es cuestión baladí porque, al calificarse de indirecta, (1) su prohibición pierde gas, como se comprueba con la STC 24/2011, de 14 de marzo, y (2) dificulta el reclamo de los hombres dedicados al cuidado de sus hijos/as, de ahí la necesidad de acudir, en la STC 26/2011, de 14 de marzo, a una extraña discriminación por circunstancias personales / familiares para amparar a aquellos hombres dedicados al cuidado de sus hijos/as. Como concluyen Jaime CABEZA PEREIRO / Marta FERNÁNDEZ PRIETO, "la discriminación que se produce (en la STC 26/2011) ... es por razón de sexo, sin que resulte provechoso, ni práctico, ni deseable, que se recurra a la cláusula general de cualquier otra condición o circunstancia personal o social, pues tal invocación incrementa la inseguridad jurídica y al tiempo, empequeñece el ámbito objetivo del sexo como elemento intolerable de diferencia entre dos situaciones comparables. Es más aconsejable utilizar moldes jurídicos más conocidos y aferrarse a doctrinas consolidadas, para evitar que se emprendan caminos que, a la larga, puedan no llevar a ninguna parte", "Comentario a las SSTC 24 y 26/2011, de 14 de marzo", Relaciones Laborales, 27, 2011.

IQUAL. REVISTA DE GÉNERO E IGUALDAD, 2022, 5, 1-27

ISSN. 2603-851X

DOI. http://dx.doi.org/10.6018/iqual.498191
} 
de la prohibición de despido de la trabajadora embarazada (sin necesidad de acreditar el conocimiento empresarial del embarazo), considerando irrazonable la solución contraria porque vulnera el derecho a la tutela judicial ex artículo 24 de la CE.

\subsection{Un tropiezo en la evolución: la Gran Crisis (2008-2017)}

Recién aprobada la Ley Orgánica de Igualdad, comienza la que se ha denominado como la Gran Crisis que, desde 2008, afectó intensamente a España y, como todos los fenómenos sociales y más si se trata de crisis económicas, tuvo un importante impacto de género. A nivel general (no es momento de análisis más detallados), las reformas acometidas a causa de la crisis en virtualmente todas las leyes laborales, funcionariales y de protección social han provocado importantes retrocesos y demoras en la evolución, aunque también hubo algunos avances tímidos y/o puntuales.

El Real Decreto Ley 10/2010, de 16 de junio, de medidas urgentes para la reforma del mercado de trabajo, la Ley 35/2010, de 17 de septiembre, de igual título, y el Real Decreto Ley $3 / 2012$, de 10 de febrero, de medidas urgentes para la reforma del mercado laboral, y la Ley 3/2012, de 6 de julio, de igual título, fueron los buques insignia de la reforma del mercado de trabajo con un recorte de derechos que, aunque han afectado a ambos sexos, ha tenido más incidencia negativa sobre quienes, usualmente mujeres, tenían trabajos atípicos o asumían responsabilidades familiares. Además, se reformó el artículo 37.6 del ET para limitar la autoorganización de las personas trabajadoras en el ejercicio de la reducción de jornada por razones de conciliación, al exigir sea reducción diaria, sin poderla concentrar en uno o varios días ${ }^{27}$. Retrocesos ni de lejos compensados con modificaciones más programáticas que efectivas (por ejemplo, las mejoras de redacción de las cláusulas de prohibición de discriminación, tanto en general como en particular en clasificación, formación profesional, promoción y ascensos acometidas en los artículos 17, 22, 23 y 24 del ET).

La Ley 27/2011, de 1 de agosto, sobre actualización, adecuación y modernización de la Seguridad Social, estableció, como reformas más destacadas, la demora de los 65 a los 67 años la edad ordinaria de jubilación y la ampliación de 15 a 25 años el periodo de cálculo de su base reguladora. Siendo estas sus dos reformas estrella, la conclusión inmediata es que las mujeres, que suelen interrumpir su trabajo para cuidar a sus hijos/as y a su familia (es el fenómeno que se conoce como el grifo que gotea), tendrán más difícil el acceso a pensiones dignas de jubilación en el brazo contributivo de la

\footnotetext{
${ }^{27}$ María Amparo BALLESTER PASTOR, "De cómo la reforma operada por el Real Decreto ley 3/2012 ha degradado el derecho fundamental a la conciliación de responsabilidades", Revista de Derecho Social, 57, 2012, pp. 99 y 100. También Alexandre PAZOS PÉREZ concluye que "la reforma tiende a conceder al empresario un mayor poder de disposición del tiempo del trabajador, lo que en la práctica dificultará la conciliación de la vida personal, laboral y familiar", "La reducción de jornada tras las últimas reformas legislativas", en Marta FERNÁNDEZ PRIETO / Jaime CABEZA PEREIRO (dirs.), Políticas de conciliación, permisos parentales y empleo, Editorial Bomarzo, Albacete, 2012, página 242.

IQUAL. REVISTA DE GÉNERO E IGUALDAD, 2022, 5, 1-27 
Seguridad Social. Tampoco aquí estos retrocesos se compensan con una pequeña ampliación de los periodos de ocupación cotizada por cuidado de hijos, o con una integración sin desempleo de las empleadas de hogar en el régimen general.

Un ejemplo emblemático de demora en la evolución fue la ampliación de dos a cuatro semanas del permiso de paternidad ${ }^{28}$, que se instauró en la Ley 9/2009, de 6 de octubre, pero fue periódicamente aplazado sin haber entrado en vigor hasta el 1.1.2017.

Los avances más significativos en este periodo de crisis económica vinieron de la mano de resoluciones judiciales que obligaron a cambios legislativos: la STJUE de 30.9.2010, Caso Roca Álvarez, C-104/09, obligó a un cambio en la titularidad del permiso de lactancia para hacerla indistinta; la STJUE de 22.11.2012, Caso Elbal Moreno, C-385/11, y la STC 61/2013, de 14 de marzo, obligaron a eliminar el cómputo discriminatorio de las carencias en el trabajo a tiempo parcial (aunque no se consiguió eliminar del todo como lo vino a demostrar la más moderna STC 91/2019, de 3 julio).

\section{Novedades legales en materia de igualdad}

\subsection{Las reformas de las normativas sobre igualdad y violencia}

La Gran Crisis fue poco a poco cediendo. Las subidas del salario mínimo interprofesional, desde 2017, han sido significativas, y ello tiene un importante impacto de género dado que las mujeres ocupan los niveles salariales más bajos. También se incrementó el permiso de paternidad, pasando a tener, desde 2017, una duración de cuatro semanas y, desde 2018, de cinco semanas. Y también desde 2017 se introdujo un complemento de pensiones a favor de las mujeres con dos o más hijos con el fin de compensar su aportación demográfica y los hándicaps profesionales de la maternidad (aunque la defectuosa configuración jurídica del complemento, estableciendo una titularidad femenina sin posibilidad de acceso de los varones, ha determinado su consideración como discriminatorio en la STJUE de 12.12.2019, Caso WA, C-450/18).

Además, el cambio de gobierno acaecido en 2018 ha traído consigo una potente reintroducción de la igualdad efectiva de mujeres y hombres en la agenda normativa.

En el ámbito laboral, el Real Decreto ley 6/2019, de 1 de marzo, de medidas urgentes para garantía de la igualdad de trato y de oportunidades entre mujeres y hombres en el

\footnotetext{
${ }^{28}$ Para comprender la importancia de la conciliación masculina a los efectos de alcanzar la igualdad, me permito remitir a José Fernando LOUSADA AROCHENA, Permiso de paternidad y conciliación masculina, Editorial Bomarzo (Albacete, 2008). También María Amparo GARCÍA RUBIO, "La tutela del trabajador varón en el ejercicio de los derechos de conciliación de la vida familiar y laboral", en Jaime CABEZA PEREIRO / Belén FERNÁNDEZ DOCAMPO (dirs.) Conciliación de la vida familiar y laboral y corresponsabilidad entre sexos, Editorial Tirant lo Blanch (Valencia, 2011), y por Marta FERNÁNDEZ PRIETO en "La tutela judicial del varón en el ejercicio de los derechos de conciliación para garantizar un empleo femenino de calidad", en Políticas de conciliación, permisos ..., obra citada.

IQUAL. REVISTA DE GÉNERO E IGUALDAD, 2022, 5, 1-27

ISSN. 2603-851X

DOI. http://dx.doi.org/10.6018/iqual.498191
} 
empleo y la ocupación ${ }^{29}$, ha supuesto la introducción de importantes reformas: se obliga a las empresas de más de 50 trabajadores a establecer un plan de igualdad (el límite hasta entonces estaba en 250 trabajadores); se establecen medidas dirigidas a erradicar las discriminaciones retributivas, obligando a las empresas una mayor transparencia en relación con las retribuciones abonadas a su personal e imponiendo auditorias salariales; se incrementa la duración del permiso de paternidad hasta 8 semanas para 2019, hasta 12 semanas para 2020 y hasta 16 semanas para 2021, equiparándose a la maternidad; se reforma en profundidad el viejo permiso de lactancia reconvirtiéndolo en un permiso para el cuidado del lactante individual para cada progenitor y con una cobertura económica parcial a través de la creación de una nueva prestación de seguridad social; se reconoce un derecho a la adaptación de la jornada por motivos de conciliación de la vida personal y familiar que supone potenciar el derecho a la presencia de aquellos trabajadores/as que, en vez de utilizar permisos, reducciones de jornada o excedencias por razones de conciliación, deciden mantenerse en su puesto de trabajo pero flexibilizando la jornada para atender las necesidades de la conciliación.

Interesantes son también sus desarrollos reglamentarios: el Real Decreto 901/2020, de 13 de octubre, por el que se regulan los planes de igualdad y su registro; y el Real Decreto 902/2020, de 13 de octubre, de igualdad retributiva mujeres y hombres.

En el ámbito de la protección social, el Real Decreto-ley 3/2021, de 2 de febrero, por el que se adoptan medidas para la reducción de la brecha de género, ha reformado el complemento de pensiones con la finalidad de sortear las objeciones de discriminación, lo que se ha hecho manteniendo su reconocimiento general a las mujeres aunque posibilitando el acceso de los varones al complemento en determinadas condiciones.

En el ámbito penal se encuentran pendientes dos proyectos legislativos con un importante impacto de género: el de reforma de la Ley de Enjuiciamiento Criminal, y el de garantía integral de la libertad sexual. Pero su análisis ya excedería de estas líneas.

Nos encontramos, en consecuencia, con un nuevo periodo de avance en la igualdad de género: ¿otra década prodigiosa? Aunque lo deseable es que sea definitiva.

\subsection{Otro tropiezo en la evolución: la pandemia COVID-19}

Esta potenciación normativa sin embargo se ha visto afectada por la pandemia COVID-19. Aunque no es ahora el momento de entrar en profundidad en esta cuestión (abordada ya en otros estudios doctrinales ${ }^{30}$ ), sí es momento de destacar que la

\footnotetext{
29 Una crítica al formato utilizado, y sus consecuencias, en María Amparo BALLESTER PASTOR, "EI RDL 6/2019 para la garantía de la igualdad de trato y de oportunidades entre mujeres y hombres en el empleo y la ocupación: Dios y el diablo en la Tierra del Sol", Revista Femeris, vol. 4, núm. 2, 2019.

$3^{\circ}$ Véase María Dolores FERNÁNDEZ GALIÑO / José Fernando LOUSADA AROCHENA, "COVID-19 e igualdad de género", Femeris: Revista Multidisciplinar de Estudios de Género, Vol. 6, núm. 1, 2021.

IQUAL. REVISTA DE GÉNERO E IGUALDAD, 2022, 5, 1-27 
pandemia pone en riesgo el nivel de igualdad de género alcanzado con anterioridad, pero también puede constituir una oportunidad de mejora si los poderes públicos introducen la perspectiva de género en el corazón de la reconstrucción. Más que nunca el principio de transversalidad de la igualdad de trato y oportunidades entre mujeres y hombres debe ser considerado al momento de elaboración de las normas antipandemia $y$, en general, de las normas dictadas para la reconstrucción del país tras la pandemia.

\section{Bibliografía}

Alonso Olea, M. (1961). La Ley del 24 de julio de 1961 sobre derechos políticos, profesionales y de trabajo de la mujer, Revista de la Administración Pública, 36.

Alonso Olea, M. (1985). Jurisprudencia constitucional sobre Trabajo y Seguridad Social, Tomos III, IV y V, (1985, 1986 y 1987, respectivamente) Madrid, España: Civitas.

Albero García, R. (2004). Las perspectivas de género en Derecho Penal: algunas reflexiones. Cuadernos de derecho judicial, 3, 449-492.

Balaguer Callejón, M.L. (2005). Mujer y Constitución. La construcción jurídica del género, Madrid, España: Cátedra.

Ballester Pastor, M.A. (2019). El RDL 6/2019 para la garantía de la igualdad de trato y de oportunidades entre mujeres y hombres en el empleo y la ocupación: Dios y el diablo en la Tierra del Sol, Revista Femeris, vol. 4, 2.

Ballester Pastor, M.A. (2012). De cómo la reforma operada por el Real Decreto ley 3/2012 ha degradado el derecho fundamental a la conciliación de responsabilidades, Revista de Derecho Social, 57.

Ballester Pastor, M.A. (2000). La Ley 39/1999 de conciliación de la vida familiar y laboral: Una corrección de errores con diez años de retraso, Valencia, España: Tirant lo Blanch.

Barrère Unzueta, M.A. (2019). Feminismo y Derecho (Fragmentos para un derecho antisubordiscriminatorio), Santiago de Chile, Chile: Olejnik.

Cabeza Pereiro, J. y Fernández Prieto, M. (2011). Comentario a las SSTC 24 y 26/2011, de 14 de marzo, Relaciones Laborales, 27.

Espuny i Tomás, M.J. (2006-2008). Aproximación histórica al principio de igualdad de género: (I) Propósitos y realidades en la II República Española. (II) El femenino después de la Guerra. (III) Las Reglamentaciones de Trabajo, observatorios de la desigualdad. (IV) De la Ley de Contrato de Trabajo de 1944 a las últimas disposiciones franquistas, Iuslabor, 3/2006, 1/2007, 2/2007 y 1/2008.

Fernández Galiño, M.D. y Lousada Arochena, J.F. (2021). COVID-19 e igualdad de género, Femeris: Revista Multidisciplinar de Estudios de Género, Vol. 6, 1.

Fernández Prieto, M. (2012). La tutela judicial del varón en el ejercicio de los derechos de conciliación para garantizar un empleo femenino de calidad. En M. 
Fernández Prieto y J. Cabeza Pereiro (dirs.), Políticas de conciliación, permisos parentales y empleo, Albacete, España: Bomarzo.

Fernández-Sancho Tahoces, A.S. (2011). La evolución de la situación de la mujer en el Derecho civil español. En L. López de la Cruz y M. Otero Crespo (coord.), M.P. García Rubio, y M.R. Valpuesta Fernández (dir.). El levantamiento del velo: Las mujeres en el Derecho Privado, Valencia, España: Tirant lo Blanch.

García Rubio, M.A. (2011). La tutela del trabajador varón en el ejercicio de los derechos de conciliación de la vida familiar y laboral. En J. Cabeza Pereiro y B. Fernández Docampo (dir.), Conciliación de la vida familiar y laboral y corresponsabilidad entre sexos, Valencia, España: Tirant lo Blanch.

Gil Ruíz, J.M. (2018). El Convenio de Estambul como marco de derecho antisubordiscriminatorio, Madrid, España: Dykinson.

Gil Ruíz, J.M. (1996). Las políticas de igualdad en España: avances y retrocesos, Granda, España: Universidad de Granada.

Loexenstein, K. (1986). Teoría de la Constitución, Barcelona, España: Ariel.

López y López, Á.M. (2011). Diversidad, feminismo y principio de igualdad. En López de la Cruz, L y Otero Crespo, M. (coord.), M. P. García Rubio y M. R. Valpuesta Fernández (dir.). El levantamiento del velo: Las mujeres en el Derecho Privado, Valencia, España: Tirant lo Blanch.

Lousada Arochena, J.F (2020). El enjuiciamiento de género, Madrid, España: Dykinson.

Lousada Arochena, J.F (2014). El derecho fundamental a la igualdad efectiva de mujeres y hombres, Valencia, España: Tirant lo Blanch.

Lousada Arochena, J.F (2009). Permiso de paternidad y conciliación masculina, Albacete, España: Bomarzo.

Lousada Arochena, J.F (2008). Unos apuntes sobre las llamadas cuotas electorales a la vista de la decisión de su constitucionalidad, Diario La Ley, 6918.

Lousada Arochena, J.F (2004). El informe sobre el impacto de género en la elaboración normativa, Aequalitas: Revista jurídica de igualdad de oportunidades entre mujeres y hombres, 15 .

Lousada Arochena, J.F (1996). El cómputo de la carencia para las prestaciones de seguridad social en los contratos de trabajo a tiempo parcial, Poder Judicial, 43/44.

Mellado Prado, P. y Gómez Sánchez, Y. (1986). En torno a la posible inconstitucionalidad del apartado 1 del artículo 57 de la Constitución Española de 1978, Revista de Derecho Político, 22.

Mora Cabello de Alba, L. (2007). Del malabarismo cotidiano a una nueva civilización más allá de la igualdad. La reconciliación de la vida laboral y familiar, Revista de Derecho Social, 37. 
Ollero Tassara, A. (1999). Discriminación por razón de sexo, Madrid, España: CEPC.

Pazos Pérez, A. (2012) La reducción de jornada tras las últimas reformas legislativas. En M. Fernández Prieto y J. Cabeza Pereiro (dirs.), Políticas de conciliación, permisos parentales y empleo, Albacete, España: Bomarzo.

Pérez del Río, M.T. (1984). El principio de igualdad: no discriminación por razón de sexo en el Derecho del Trabajo, Madrid, España: Instituto de Estudios Laborales y de la Seguridad.

Pérez Garzón, J.S. (2011). Historia del feminismo, Madrid, España: Los Libros de la Catarata.

Quintanilla Navarro, B. (1994). Igualdad de retribución por razón de sexo. En F. Valdés Dal Ré, La reforma del mercado Laboral, Valladolid, España: Lex Nova.

Rey Martínez, F. (1995). El derecho fundamental a no ser discriminado por razón de sexo, Madrid, España: Editorial Mc Graw Hill.

Rodríguez-Piñero y Bravo-Ferrer, M. (2004). El informe sobre el impacto por razón de género en la elaboración de las disposiciones normativas, Relaciones Laborales, 1 .

Rodríguez-Piñero y Bravo-Ferrer, M. y Fernández López, M.F. (1986). Igualdad y discriminación, Madrid, España: Editorial Tecnos.

Ruíz Resa, J.D. (2000). Trabajo y Franquismo. Granda, España: Comares.

Ruíz-Rico López-Lendínez, J.J. (1991). El sexo de Sus Señorías, Madrid, España: Ediciones Temas de Hoy.

Tamayo Haya, S. (2011). La posición jurídica de la mujer a través de las reformas del Derecho de familia. En L. López de la Cruz y M. Otero Crespo (coord.), M.P García Rubio y M.R. Valpuesta Fernández (dir). El levantamiento del velo: Las mujeres en el Derecho Privado, Valencia, España: Tirant lo Blanch.

Ventura Franch, A. y García Campá, S. (2018). El derecho a la igualdad efectiva de mujeres y hombres. Una evaluación del primer decenio de la Ley Orgánica 3/2007, Madrid, España: Aranzadi.

Ventura Franch, A. (1999). Las mujeres y la Constitución Española de 1978, Madrid, España: Instituto de la Mujer.

Cómo referenciar este artículo/How to reference this article:

Lousada Arochena, J.F. (2022). Evolución de la igualdad desde la constitución de 1978. iQUAL. Revista de Género e lgualdad, 5, 1-27, doi: 10.6018/iqual.498191

Lousada Arochena, J.F. (2022). Evolución de la igualdad desde la constitución de 1978. [Evolution of equality since the 1978 Constitution: from strong patriarchy to gender equality]. iQUAL. Revista de Género e lgualdad, 5, 1-27, doi: 10.6018/iqual.498191 